\title{
Effect of exogenous hormones on ovulation and gonadal steroid plasma levels in starry flounder, Platichthys stellatus
}

\author{
Han Kyu Lim ${ }^{1}$
}

Received: 1 July 2015/Accepted: 11 January 2016/Published online: 25 January 2016

(C) The Author(s) 2016. This article is published with open access at Springerlink.com

\begin{abstract}
The present study was designed to examine the potential for inducing ovulation in starry flounder (Platichthys stellatus) using gonadotropin-releasing hormone analog (GnRHa) and human chorionic gonadotropin (hCG) to assess whether starry flounder are differentially responsive to GnRHa and hCG. Female starry flounder were injected or implanted with different doses of hCG or GnRHa pellets to examine their ovulationinducing potential and effects on plasma levels of testosterone (T), 17 $\beta$-estradiol (E2), and 17,20 $\beta$-dihydroxy-4-pregnen-3-one (17,20 $\beta \mathrm{P})$. Blood samples were collected for up to 10 or 25 days post-injection or post-implantation in two separate experiments designed to mimic the early and middle stages of spawning, respectively. Fish treated with the GnRHa pellets $(100 \mu \mathrm{g})$ showed a significant increase in the total number of stripped eggs relative to the controls. GnRHa administration had no effect on the floating rate or fertilization rate of ovulated eggs in the both experiments, whereas hCG injection affected both of these rates. Plasma T levels were not significantly different between the exogenous hormonetreated and control fish. In contrast, the plasma E2 level was elevated in those fish treated with GnRHa, regardless of injection or implantation, and was accompanied by increased numbers of stripped eggs in both experiments. Treatment with GnRHa resulted in higher $17,20 \beta \mathrm{P}$ levels compared to the controls, and there was a positive relationship between elevated plasma 17,20ßP and an increase in ovulated eggs in response to GnRHa treatment. The implantation of starry flounder with GnRHa-containing pellets was effective at inducing sustained ovulation compared to hCG treatment.
\end{abstract}

Keywords Starry flounder · Platichthys stellatus · Ovulation · Gonadotropin-releasing hormone analog $\cdot$ Human chorionic gonadotropin · Gonadal steroid

Han Kyu Lim

limhk@mokpo.ac.kr; limhq69@hanmial.net

1 Department of Marine and Fisheries Resources, Mokpo National University, Jeonnam 534-729,

Republic of Korea 


\section{Introduction}

Starry flounder (Platichthys stellatus) is widely distributed throughout the northern Pacific Ocean, including coastal waters of Korea, Japan, Russia, Canada, and North America. There is growing interest in developing starry flounder aquaculture in Korea and China; however, current techniques are limited by unreliable egg production, similar to many other marine flatfish species. Therefore, the mass yield of viable eggs is the first consideration in developing the commercial culture of this species. In cultured stocks of starry flounder, most females exhibit reproductive dysfunction, including a failure to ovulate and low-quality egg production. A variety of approaches have been used to address these problems, most of which involve artificial manipulation of the endocrine system. These treatments act at different levels in the hypothalamic-pituitary-gonadal axis, and they typically involve treatment with pituitary homogenates, purified gonadotropin preparations, and, more recently, synthetic agonists of gonadotropin-releasing hormone (GnRHa) (reviewed by Zohar and Mylonas 2001).

The injection of piscine or mammalian gonadotropins ( $\mathrm{GtHs}$ ) has been used successfully to induce ovulation in a wide range of species (Donaldson and Hunter 1983; Pankhurst 1998; Poortenaar and Pankhurst 2000; Zohar and Mylonas 2001; King and Pankhurst 2004; Wang et al. 2010). In addition, GnRHa has now been successfully tested in a range of marine and freshwater species and has been shown to be effective in improving egg quantity and quality (Lee et al. 1986, 1987; Poortenaar and Pankhurst 2000; Zohar and Mylonas 2001; King and Pankhurst 2004). GnRHa is a principal stimulator of follicle-stimulating hormone and luteinizing hormone (LH) release in teleost fish. GnRHa stimulates LH release by the pituitary, which in turn promotes the maturational competence of oocytes and production of maturation-inducing steroids (MISs) from the ovary. In many fish, the progesterone 17,20 $\beta$-dihydroxy-4-pregnen-3-one $(17,20 \beta \mathrm{P})$ does this. The MISs secreted by the induced follicle promote synthesis of the maturation-promoting factor responsible for the resumption of meiotic division and, consequently, oocyte ovulation (Nagahama 1994; Zohar and Mylonas 2001).

If a specific GtH assay was developed for a target fish species, GtH would be a suitable indicator of gonadal development in fish. However, GtH assays are currently limited in most fish; therefore, sex steroids remain the most useful endocrine markers. Testosterone (T) and 17 $\beta$-estradiol (E2) are commonly measured indicators of ovarian development, and $17,20 \beta$ P is the putative MIS (Poortenaar and Pankhurst 2000).

Treatment of fish with exogenous hormones by injection typically results in the shortterm induction of ovulation and changes in plasma steroids (Ramos 1986; Haddy and Pankhurst 2000; Poortenaar and Pankhurst 2000; Levavi-Sivan et al. 2004; Denson et al. 2007). Treatment of fish with slow-release forms of GnRHa, injection with GnRHa microspheres, or implantation with GnRHa-containing pellets typically results in the slow but stable induction of ovulation over a long period (Lee et al. 1986; Harmin and Crim 1992; Berlinsky et al. 1997; Mylonas and Zohar 2001; King and Pankhurst 2004). Dosesustained GnRHa release stimulates multiple ovulations, but in some species it also stimulates ovarian development in immature fish (Poortenaar and Pankhurst 2000). Therefore, GtH preparations have now been largely replaced by GnRHa treatment.

In the absence of reliable natural ovulation in cultured stocks, starry flounder egg production currently depends on induced ovulation using exogenous hormones. Thus, it is important to characterize the response to these treatments. Protocol development for brood stock management has included studies of the effects of GnRHa on the stimulation of milt 
production and spermiation in male starry flounder (Lim et al. 2002; Moon et al. 2003; Lim and Kim 2007). Treatment of male starry flounder with GnRHa increased the milt volume, confirming the role of $\mathrm{GtH}$ in stimulating milt volume increase in this species over long periods. However, the effects of GnRHa on ovulation and egg quality remain unknown.

The aim of this study was to determine the potential for inducing ovulation in starry flounder using GnRHa and human chorionic gonadotropin (hCG) to assess whether starry flounder are differentially responsive to GnRHa and hCG, based on the dose and delivery mode over short and long periods. The response to GnRHa and hCG treatment was assessed in terms of the total number of eggs ovulated, the floating rate, and the fertilization rate of the eggs produced. Endocrine effects were assessed by measuring the plasma levels of E2, T, and 17,20ßP.

\section{Materials and methods}

\section{Fish and sampling}

Female flounder were randomly selected from stocks grown at the East Sea Mariculture Research Center, National Fisheries Research and Development Institute, Uljin, Korea. During the experiment, the fish were maintained at a natural seawater temperature (mean $\pm \mathrm{SD}, 11.0 \pm 1.0^{\circ} \mathrm{C}$ ) and photoperiod and fed daily with moist pellets for olive flounder.

In our experiments, the fish were anesthetized with $200 \mathrm{ppm}$ of ethyl 3-aminobenzoate methanesulfonate salt (Sigma, St. Louis, MO, USA), weighed, tagged for identification with PIT tags (Biomark Inc., Idaho, USA), and injected or implanted as described below. Blood samples were obtained by caudal puncture using pre-heparinized $23 \mathrm{G}$ needles. Subsequent blood samples were taken at various times post-treatment as described below. Plasma was separated from the blood by centrifugation at $18,000 \times g$ for 5 min at $4{ }^{\circ} \mathrm{C}$ and frozen at $-70{ }^{\circ} \mathrm{C}$ until hormone analysis. The numbers of total eggs and floated eggs were also measured.

\section{Experiment 1: effect of GnRHa and hCG injection early in the spawning season}

The first experiment lasted 15 days, when cultured fish are typically in the early stages of spawning (Lim et al. 2007). The mean weight of the fish used was $1503.8 \pm 245.0 \mathrm{~g}$. The fish were divided into five treatment groups, anesthetized, and treated with: (1) saline (control), (2) GnRHa salmon (Sigma) at $100 \mu \mathrm{gg}^{-1}$ body weight (BW), (3) GnRHa salmon at $200 \mu \mathrm{g} \mathrm{kg}^{-1} \mathrm{BW}$, (4) hCG (Sigma) at $50 \mathrm{IU} \mathrm{kg}^{-1} \mathrm{BW}$, and (5) hCG at $100 \mathrm{IU} \mathrm{kg}{ }^{-1} \mathrm{BW}$ ( $n=6$ fish per treatment). All treatments were administered by intramuscular injection (i.m.). Blood was collected from each fish immediately before injection (day 0 ) and at $1,3,5,6,8$, and 10 days post-injection (p.i.). At 5 days p.i., each fish received a second injection with the same dose.

\section{Experiment 2: effect of GnRHa treatment during the middle of the spawning season}

The second experiment was conducted for 30 days, when cultured fish are typically in the middle stages of spawning (Lim et al. 2007). The fish in this experiment had a mean weight 
of $1473.9 \pm 116.2 \mathrm{~g}$. Fish were implanted with either a blank pellet (control) or pellets containing either 100 or $200 \mu \mathrm{g} \mathrm{kg}^{-1} \mathrm{BW}$ ( $n=7$ fish per treatment).

GnRHa pellets were produced according to Lee et al. (1986). LHRH salmon was dissolved in $50 \%$ ethanol and mixed with cholesterol powder. The mixture was dried, combined with molten cocoa butter, and compressed into pellets. The pellets were individually prepared according to the $\mathrm{BW}$ of each fish and implanted into the dorsal muscle.

The fish were bled at the time of implantation (day 0) and at 1, 3, 5, 10, 15, 20, and 25 days post-implantation (p.im.).

\section{Hormone measurements}

Plasma steroids were extracted with ethyl acetate and the concentrations were measured using a radioimmunoassay for T, $11 \mathrm{KT}$, and 17,20 $\mathrm{PP}$ as described by Aida et al. (1984). Rabbit anti-E2-6-CMO-BSA, anti-T-6-CMO-BSA, and anti-17,20 $\beta-P-3-C M O-B S A$ sera were purchased from Cosmo Bio Co. Ltd. (Tokyo, Japan). Non-radioactive steroid standards were purchased from Steraloids Inc. (Wilton, NH, USA). Radio-labeled T and E2 $\left(\left[2,4,6,7-{ }^{3} \mathrm{H}\right]-\mathrm{T}\right.$ and $\left.\left[2,4,6,7-{ }^{3} \mathrm{H}\right]-\mathrm{E} 2\right)$ were purchased from Amersham Biosciences (Piscataway, NJ, USA). Radio-labeled 17,20 $\beta-\mathrm{P}$ was prepared from $\left[1,2,6,7-{ }^{3} \mathrm{H}\right]-17 \alpha-\mathrm{OHP}$ (Amersham Biosciences) by enzymatic conversion as described by Young et al. (1983) and separated from the parent compound by thin-layer chromatography. The assay sensitivities were $12.5,10$, and $10 \mathrm{pg} \mathrm{ml}^{-1}$ for $\mathrm{E} 2, \mathrm{~T}$, and 17,20 $\beta-\mathrm{P}$, respectively.

\section{Ovulation and egg quality measurements}

The fish were examined for ovulation by serial waves of abdominal pressure. Any eggs expressed were collected and measured with a 1000-ml glass cylinder, and their total and floating volumes recorded. The eggs were stripped daily for 15 and 30 days after treatment in both experiments, respectively. The number of eggs per $\mathrm{ml}$ was estimated (900 eggs per $\mathrm{ml}$ ) based on counts of 1-ml subsamples $(n=10)$, and the buoyant rate of the ovulated eggs was used to assess egg quality. A subsample of eggs was transferred to 250-ml glass beakers and fertilized in triplicate by adding pooled milt with filtered seawater. The eggs and milt were mixed for approximately $5 \mathrm{~min}$ and incubated at $10{ }^{\circ} \mathrm{C}$. The fertilization rate was determined after $8 \mathrm{~h}(8-16$ cells) by the microscopic examination of approximately 30 eggs per batch.

\section{Statistics}

All data are expressed as the mean \pm standard error of the mean (SEM); $t$ tests or one-way ANOVA followed by Tukey's mean comparison test was used to analyze the data with the SPSS computer package. The level of statistical significance was set at $P<0.05$.

\section{Results}

\section{Experiment 1: effect of GnRHa and hCG injection early in the spawning season}

The number of stripped eggs per $100 \mathrm{~g}$ BW increased in fish injected with $100 \mu \mathrm{g}$ of GnRHa compared with the other fish, although the difference was not significant. The 
Table 1 Effect of exogenous hormone injection on the number of stripped eggs, floating rate, and fertilization rate

\begin{tabular}{llll}
\hline Treatment & $\begin{array}{l}\text { Number of stripped } \\
\text { eggs }\left(100 \mathrm{~g}^{-1} \mathrm{BW}\right)\end{array}$ & $\begin{array}{l}\text { Floating } \\
\text { rate }(\%)\end{array}$ & $\begin{array}{l}\text { Fertilization } \\
\text { rate }(\%)\end{array}$ \\
\hline Control & $1555 \pm 1214$ & $26.5 \pm 0.6$ & $96.5 \pm 3.5^{\mathrm{c}}$ \\
GnRHa 100 & $3907 \pm 1302$ & $52.4 \pm 11.5$ & $93.1 \pm 2.6^{\mathrm{bc}}$ \\
GnRHa 200 & $1890 \pm 613$ & $51.1 \pm 11.8$ & $92.6 \pm 2.9^{\mathrm{bc}}$ \\
hCG 50 & $1405^{*}$ & $25.0 \pm 0$ & $69.0 \pm 0^{\mathrm{a}}$ \\
hCG 100 & $1882 \pm 554$ & $31.8 \pm 18.2$ & $82.4 \pm 4.2^{\mathrm{b}}$ \\
\hline
\end{tabular}

Different superscripts indicate significant differences between treatments $(P<0.05)$

* One time stripped

floating rate ranged from 25 to $54.1 \pm 11.5 \%$, and there were no differences between the experimental groups; however, the fertilization rate was lower in the 50- and 100-IU hCG group compared to the control group (Table 1). Fish injected with $50 \mathrm{IU}$ of hCG ovulated only once during the experimental period. The plasma E2 levels were significantly greater in fish treated with 100 and $200 \mu \mathrm{g}$ of GnRHa compared to the controls at 1 and 3 days p.im.; there was no difference at 6 and 10 days p.im. The plasma T levels in fish injected with GnRHa and hCG were not different from the controls at 1-5 days p.im. The plasma $17,20 \beta \mathrm{P}$ levels of the fish in the control group remained lower throughout the experiment. However, fish treated with $100 \mu \mathrm{g}$ of GnRHa were significantly elevated from 1 day p.im., compared to the control group, except at 3 days p.im. (Fig. 1).

\section{Experiment 2: effect of GnRHa treatment during the middle of the spawning season}

The number of stripped eggs per $100 \mathrm{~g} \mathrm{BW}$ in experiment 2 showed the same pattern as in experiment 1 , with a significant increase in the $100-\mu \mathrm{g}$ GnRHa pellet-treated group. There was no effect of GnRHa treatment on the floating rate and fertilization rate between the experimental groups (Table 2).

At 1 and 3 days p.im., the plasma E2 levels were significantly greater in those fish implanted with $100 \mu \mathrm{g}$ of GnRHa pellets compared to the controls, and the values decreased rapidly from 10 days p.im. The plasma T levels in those fish treated with GnRHa pellets were not different from those of the controls at any time, except at 20 and 25 days p.im., when the 100- and 200- $\mu$ g group values were lower than those of the controls. The plasma $17,20 \beta \mathrm{P}$ levels in the 100- $\mu$ g GnRHa implanted fish were significantly elevated at days 1, 3, and 5 p.im., compared to the control group (Fig. 2).

\section{Discussion}

Under culture conditions, fully grown starry flounder oocytes can be retained in the ovary without ovulation, and the stripped eggs show low fertility. Fish farmers have used various hormones to promote ovulation in hatcheries, but the results have been far from satisfactory in many cases. GnRHa and hCG treatment has been tested successfully in starry flounder males and has been shown to be an effective strategy for enhancing milt quantity 

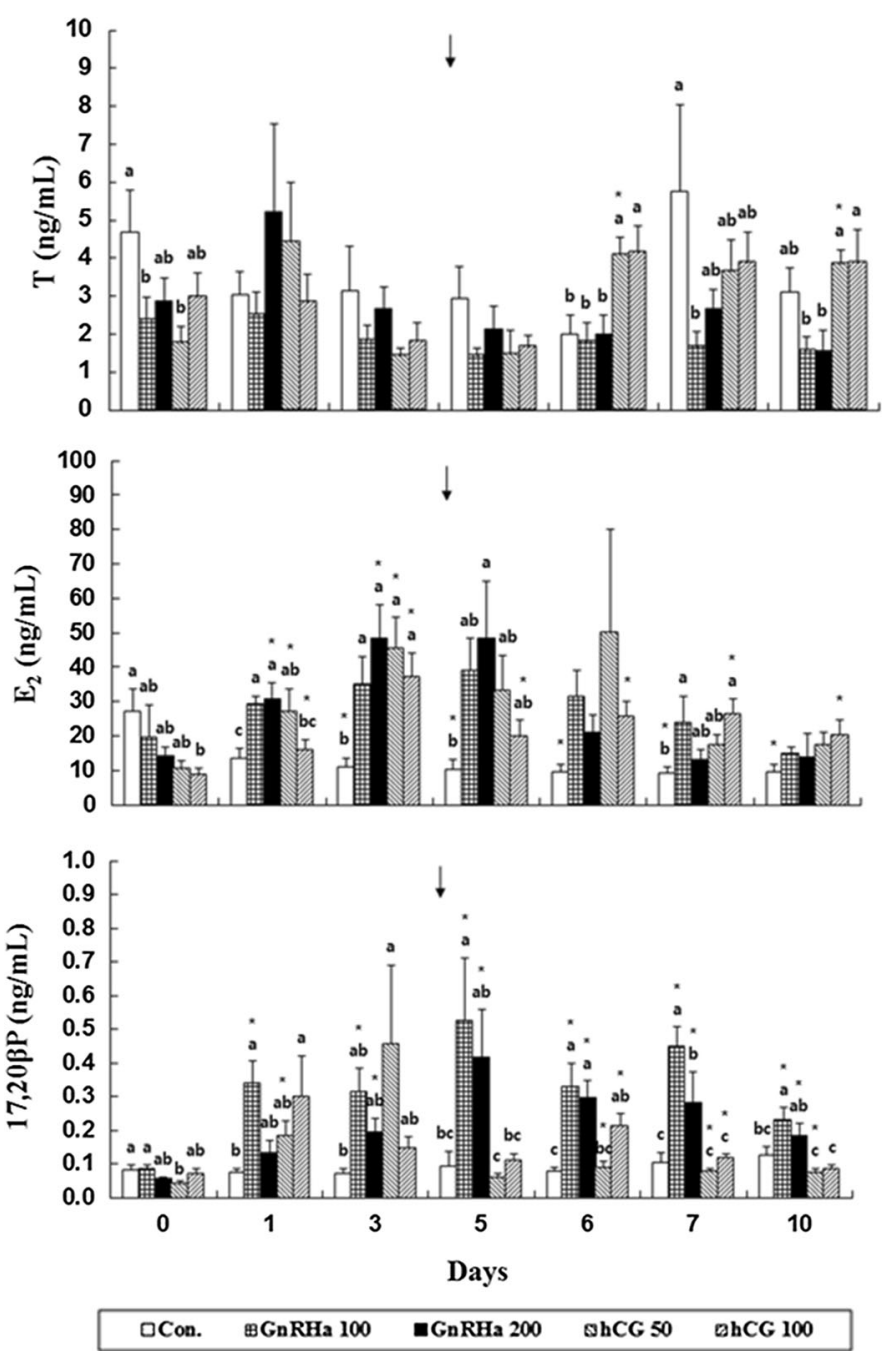

Fig. 1 Changes in plasma levels of $17 \beta$-estradiol (E2), testosterone (T), and 17,20 $\beta$-dihydroxy-4-pregnen3 -one $(17,20 \beta \mathrm{P})$ in starry flounder treated with exogenous hormone injections early in the spawning period. The superscripts indicate significant differences between treatments at that sampling time $(P<0.05)$. The arrow indicates the timing of the second injection

Table 2 Effect of exogenous hormone implantation on the number of stripped eggs, floating rate, and fertilization rate

\begin{tabular}{lccc}
\hline Treatment & $\begin{array}{l}\text { Number of stripped } \\
\text { eggs }\left(100 \mathrm{~g}^{-1} \mathrm{BW}\right)\end{array}$ & $\begin{array}{l}\text { Floating } \\
\text { rate }(\%)\end{array}$ & $\begin{array}{l}\text { Fertilization } \\
\text { rate }(\%)\end{array}$ \\
\hline Control & $4118 \pm 1886^{\mathrm{b}}$ & $51.2 \pm 6.7$ & $84.1 \pm 3.5$ \\
GnRHa 100 & $16,913 \pm 2307^{\mathrm{a}}$ & $41.9 \pm 6.2$ & $85.3 \pm 5.5$ \\
GnRHa 200 & $7421 \pm 2149^{\mathrm{b}}$ & $42.8 \pm 5.2$ & $84.3 \pm 4.5$ \\
\hline
\end{tabular}

Different superscripts indicate significant differences between treatments $(P<0.05)$ 

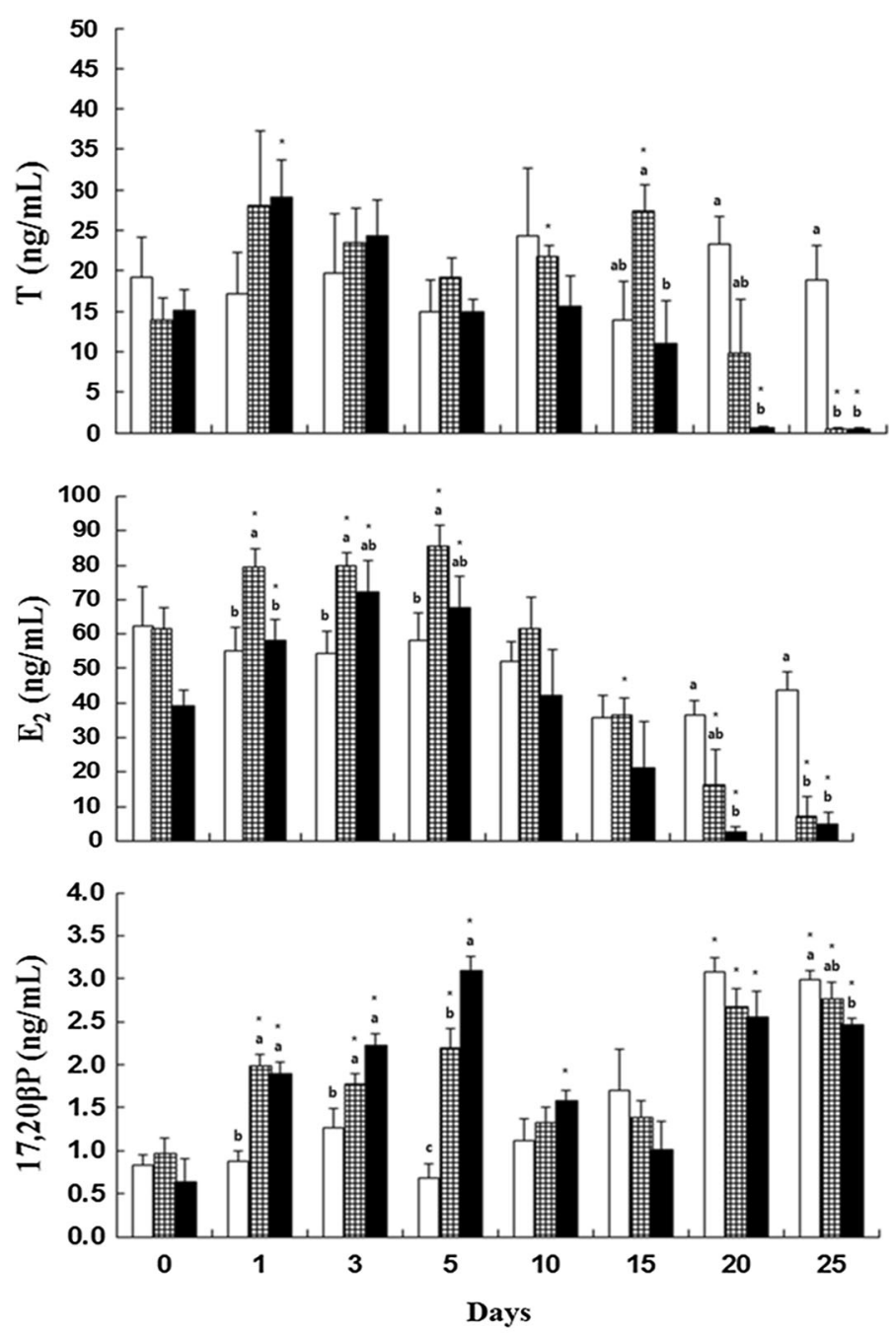

$\square$ Con. BGnRHa $100 \quad$ GnRHa 200

Fig. 2 Changes in the plasma levels of 17 $\beta$-estradiol (E2), testosterone (T), and 17,20 $\beta$-dihydroxy-4pregnen-3-one $(17,20 \beta \mathrm{P})$ in starry flounder treated with exogenous hormone injections in the middle of the spawning season. The superscripts indicate significant differences between treatments at that sampling time $(P<0.05)$

(Lim et al. 2002; Moon et al. 2003; Lim and Kim 2007). hCG and GnRHa, administered short or long term via injection or pellet implant, increased the milt volume in previous experiments with starry flounder (Lim et al. 2002; Moon et al. 2003; Lim and Kim 2007). However, the effect of exogenous hormones on starry flounder ovulation is unknown. In the present study, GnRHa administered either by injection or pellet implantation induced successful ovulation in starry flounder. Most ovulations caused by GnRHa administration occurred on consecutive days and were accompanied by significant increases in egg 
quantity. The results of the present study and of a previous study on oocyte development (Lim et al. 2007) suggest that female starry flounder are multiple ovulators and have multiple groups of synchronous oocyte batches. The finding of repeated ovulation in response to treatment with GnRHa is consistent with findings in other flatfish, yellowtail flounder (Pleuronectes ferrugineus) (Larsson et al. 1997), summer flounder (Paralichthys dentatus) (Berlinsky et al. 1997), and greenback flounder (Rhombosolea tapirina) (Poortenaar and Pankhurst 2000). However, it is unclear whether oocytes are recruited at certain developmental stages because of a lack of solid information on starry flounder ovarian cycling. In some species, hCG induces ovulation (Lam 1982; Peter et al. 1988) and produces high fertility, but not in summer flounder (like starry flounder in this study). Therefore, it may be dose, origin of exogenous hormone, and/or maturity level related. In many teleost species, mammalian GtHs have potencies that are orders of magnitude lower than teleost GtHs (Pankhurst 1998). Thus, large and repeated doses are required to induce ovulation upon hCG treatment (Smigielski 1975; Lam 1982; Donaldson and Hunter 1983; Berlinsky et al. 1997). Poortenaar and Pankhurst (2000) used a much greater concentration (1000 IU hCG kg-1 $\mathrm{BW}$ ) to induce ovulation in greenback flounder compared with the present study (50-100 IU hCG kg-1 BW). Similarly, a lower dose of hCG by injection (250 IU kg $\mathrm{g}^{-1} \mathrm{BW}$ ) was ineffective at inducing ovulation in summer flounder (Berlinsky et al. 1997). However, a relatively low dose of hCG (275 IU kg BW) induced ovulation in cobia (Rachycentron canadum) (Caylor et al. 1994).

In the present study, egg quantity and hormone secretion were significantly increased by GnRHa treatment regardless of the dose, though there was no treatment effect of GnRHa on the floating rate and fertilization rate between the experimental groups in experiment 2 . This suggests that the optimal effective dose of GnRHa varies between species and that the degree of maturity and GnRHa pellet matrix are important for successful ovulation (Sherwood et al. 1988). Similar to greenback flounder, GnRHa (200 $\mu \mathrm{g}$, ini) pellet implantation resulted in fewer ovulations and a smaller number of eggs ovulated compared to treatment with $100 \mu \mathrm{g}$ of GnRHa (ini) and pellet implantation in this study (Poortenaar and Pankhurst 2000). Previous studies have shown that the optimal effective dose of GnRHa is species-specific: 1-5 $\mu \mathrm{g}$ in milkfish (Chanos chanos) (Tamaru et al. 1988), 6.3-23.6 $\mu \mathrm{g}$ in black sea bass (Centropristis striata) (Berlinsky et al. 2005), $70 \mu \mathrm{g}$ in chum salmon (Oncorhynchus keta) (Park et al. 2007), and 300-400 $\mu \mathrm{g}$ in gray mullet (Mugil cephalus) (Lee et al. 1987).

Egg quality is an important term of reference following the successful induction of spawning in fish. Despite significant increases in the total number of stripped eggs, egg quality was not affected by the implantation of GnRHa pellets or injection of GnRHa in starry flounder, because the floating rate and fertilization rate were not significantly different between the control and GnRHa-treated groups. However, the hCG-injected groups showed lower egg fertility in this study. This could be due to the use of unsuitable doses of hCG for spawning induction, as reported previously for common sole (Solea solea) (Ramos 1986) or over-ripening of the egg after exogenous hormone treatment such as in Japanese flounder (Limanda yokohamae) (Hirose et al. 1979). Premature seasonal hormone treatment may induce precocious egg maturation and ovulation, causing low egg fertility in coho salmon (Oncorhynchus kisutch) (Hunter et al. 1981; Fitzpatrick et al. 1984).

The injection of exogenous hormones typically results in the short-term induction of ovulation, as well as changes in plasma steroids. Treatment of fish with slow-release forms of exogenous hormones such as microspheres or pellets typically produces slower but more sustained ovulation (Poortenaar and Pankhurst 2000; Zohar and Mylonas 2001). In this study, plasma $\mathrm{T}$ levels did not significantly increase upon exogenous hormone treatment during the early and middle parts of the spawning season. As mentioned in Poortenaar and 
Pankhurst (2000), this may be the result of the rapid aromatization of $\mathrm{T}$ and/or detrimental effects of stress on plasma steroid levels. Stress has been reported to depress plasma levels of gonadal steroids in many species (Pankhurst 2011). The plasma E2 level was elevated in fish induced to spawn by GnRHa treatment in the present study. The elevated level of E2 likely resulted from the steroidogenic activity of developing vitellogenic follicles. In this study, the plasma levels of $17,20 \beta \mathrm{P}$ were consistently elevated in association with reproductive events in both experiments, similar to wild greenback flounder (Barnett and Pankhurst 1999). Several studies have indicated that the maturational steroid 17,20 $\beta$ P is involved in regulating spermiation and ovulation in most teleosts (reviewed in Pankhurst

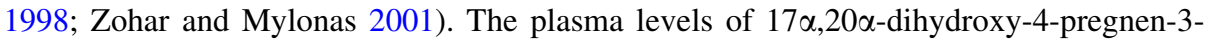
one, 11-deoxycortisol, and 5 $\beta$-reduced pregnane were found to be at least as high as that of 17,20ßP in previous studies (Canario and Scott 1990; Scott et al. 1991). Additional studies are required to confirm the existence of such steroids in starry flounder plasma, and the potency of these candidate MISs in inducing oocyte maturation in vivo. In the present study, GnRHa treatment was more potent and efficient than hCG treatment. As mentioned by Zohar and Mylonas (2001), this is because GnRH provides more balanced stimulation of reproductive events and, presumably, better integration of these events with other physiological functions by directly or indirectly affecting the release of other hormones necessary for successful final oocyte maturation, spermiation, and spawning.

The implantation of starry flounder with GnRHa-containing pellets was effective at inducing sustained ovulation compared to hCG treatment. Although future studies of the optimal doses of GnRHa, use of anti-dopaminergic drugs, and timing of treatment are needed to produce high-quality eggs in starry flounder, it is clear that GnRHa pellets can be applied to starry flounder hatchery processes without compromising egg quality or fertility.

Acknowledgments The present study was supported by project at National Fisheries and Development Institute.

Open Access This article is distributed under the terms of the Creative Commons Attribution 4.0 International License (http://creativecommons.org/licenses/by/4.0/), which permits unrestricted use, distribution, and reproduction in any medium, provided you give appropriate credit to the original author(s) and the source, provide a link to the Creative Commons license, and indicate if changes were made.

\section{References}

Aida K, Kato T, Awaji M (1984) Effects of castration on the smoltification of precocious male masu salmon Oncorhynchus masou. Bull Jpn Soc Sci Fish 50:565-571

Barnett CW, Pankhurst NW (1999) Reproductive biology and endocrinology of greenback Rhombosolea tapirina (Günther 1862). Mar Freshw Res 50:35-42

Berlinsky DL, King VW, Hodson RG, Sullivan CV (1997) Hormone induced spawning of summer flounder Paralichthys dentatus. J World Aquacult Soc 28:79-86

Berlinsky DL, William KV, Smith TIJ (2005) The use of luteinizing hormone releasing hormone analogue for ovulation induction in black sea bass (Centropristis striata). Aquaculture 250:813-822

Canario AVM, Scott AP (1990) Identification of, and development of radioimmunoassays for 17 $\alpha, 21$ dihydroxy-4-pregnen-3,20-dione and $3 \alpha, 17 \alpha, 21$-trihydroxy-5 $\beta$-pregnan-20-one in the ovaries of mature plaice (Pleuronectes platessa). Gen Comp Endocrinol 78:273-285

Caylor RE, Biesiot PM, Franks JS (1994) Culture of cobia (Rachycentron canadum): cryopreservation of sperm and induced spawning. Aquaculture 125:81-92

Denson MR, Jenkins WE, Berlinsky DL, Smith TIJ (2007) A comparison of human chorionic gonadotropin and luteinizing hormone releasing hormone analogue for ovulation induction in black sea bass Centropristis striata (Linnaeus, 1758). Aquac Res 38:918-925 
Donaldson EM, Hunter GA (1983) Induce final maturation, ovulation, and spermiation in cultured fish. Fish Physiol 9B:351-403

Fitzpatrick MS, Suzomoto RK, Schreck CB, Oberbilling D (1984) Luteinizing hormone-releasing hormone analogue induced precocious ovulation in adult coho salmon (Oncorhynchus kisutch). Aquaculture 43:67-73

Haddy JA, Pankhurst NW (2000) The effects of salinity on reproductive development, plasma steroid levels, fertilization and egg survival in black bream Acanthopagrus butcheri. Aquaculture 112:363-377

Harmin SA, Crim LW (1992) Gonadotropic hormone-releasing hormone analog (GnRH-A) induced ovulation and spawning in female winter flounder, Pseudopleuronectes americanus (Walbaum). Aquaculture 104:375-390

Hirose K, Machida Y, Donaldson EM (1979) Induced ovulation of Japanese flounder (Limanda yokohamae) with human chorionic gonadotropin and salmon gonadotropin, with special reference to changes in quality of eggs retained in the ovarian cavity after ovulation. Bull Jpn Soc Sci Fish 45:31-36

Hunter GA, Donaldson EM, Dye HM (1981) Induced ovulation in coho salmon (Oncorhynchus kisutch). I. Further studies on the use of salmon pituitary preparations. Aquaculture 26:117-127

King HR, Pankhurst NW (2004) Effect of maintenance at elevated temperatures on ovulation and luteinizing hormone releasing hormone analogue responsiveness of female Atlantic salmon (Salmo salar) in Tasmania. Aquaculture 233:583-597

Lam TJ (1982) Applications of endocrinology to fish culture. Can J Fish Aquat Sci 39:111-137

Larsson DGJ, Mylonas C, Zohar Y, Crim L (1997) Gonadotropin-releasing hormone analogue (GnRH-A) induces multiple ovulations of high-quality eggs in a cold-water, batch-spawning teleost, the yellowtail flounder (Pleuronectes ferrugineus). Can J Fish Aquat Sci 54:1957-1964

Lee CS, Tamaru CS, Kelley CD, Banno JE (1986) Induced spawning of milkfish, Chanos chanos, by a single application of LHRH-analogue. Aquaculture 58:87-98

Lee CS, Tamaru CS, Miyamoto GT, Kelley CD (1987) Induced spawning of grey mullet (Mugil cephalus) by LHRH-a. Aquaculture 62:327-336

Levavi-Sivan B, Vaiman R, Sachs O, Tzchori I (2004) Spawning induction and hormonal levels during final oocyte maturation in the silver perch (Bidyanus bidyanus). Aquaculture 229:419-431

Lim HK, Kim SY (2007) Effect of exogenous hormones on spermiation in the starry flounder Platichthys stellatus. J Kor Fish Soc 40:374-379

Lim HK, Han HS, Chang YJ (2002) Effects of gonadotropin-releasing hormone analog on milt production enhancement in starry flounder Platichthys stellatus. Fisheries Sci 68:1197-1204

Lim HK, Byun SG, Lee JH, Park SU, Kim YC, Han HK, Min BH, Lee BI (2007) Sexual maturity and reproductive cycle of starry flounder Platichthys stellatus cultured in indoor tank. J Aquac 20:212-218

Moon SH, Lim HK, Kwon JY, Lee JK, Chang YJ (2003) Increased plasma 17-hydroxyprogesterone and milt production in response to gonadotropin-releasing hormone agonist in captive male starry flounder, Platichthys stellatus. Aquaculture 218:703-716

Mylonas CC, Zohar Y (2001) Endocrine regulation and artificial induction of oocyte maturation and spermiation in basses of the genus Morone. Aquaculture 202:205-220

Nagahama Y (1994) Endocrine regulation of gametogenesis in fish. Int J Dev Biol 38:217-229

Pankhurst NW (1998) Reproduction. In: Pickering AD, Black KD (eds) Biology of farmed fish. Sheffield Academic Press, London

Pankhurst NW (2011) The endocrinology of stress in fish: an environmental perspective. Gen Comp Endocrinol 170:265-275

Park WD, Lee CH, Lee CS, Kim DJ, Tamaru CS, Sohn YC (2007) Effects of a gonadotropin-releasing hormone analog combined with pimozide on plasma sex steroid hormones, ovulation and egg quality in freshwater-exposed female chum salmon (Oncorhynchus keta). Aquaculture 271:488-497

Peter RE, Lin HR, Kraak GVD (1988) Induced ovulation and spawning of cultured freshwater fish in China: advances in application of GnRH analogues and dopamine antagonists. Aquaculture 74:1-10

Poortenaar CW, Pankhurst NW (2000) Effects of luteinizing hormone-releasing hormone analogue and human chorionic gonadotropin on ovulation, plasma and ovarian levels of gonadal steroids in greenback flounder Rhombosolea tapirina. J World Aquacult Soc 31:175-185

Ramos J (1986) Induction of spawning in common sole (Solea solea L.) with human chorionic gonadotropin (HCG). Aquaculture 56:239-242

Scott AP, Canario AVM, Sterwood NM, Warby CM (1991) Levels of steroids, including cortisol and 17a,20ß-dihydroxy-4-pregnen-3-one, in plasma, seminal fluid, and urine of Pacific herring (Clupea harengus pallasi) and North sea plaice (Pleuronectes platessa L.). Can J Zool 69:111-116

Sherwood NM, Crim LW, Carolsfeld J, Walters SM (1988) Sustained hormone release. I. Characteristics of in vitro release of gonadotropin releasing hormone analogue (GnRH-A) from pellets. Aquaculture $74: 75-86$ 
Smigielski AS (1975) Hormonal-Induced Ovulation of the Winter Flounder, Pseudopleuronectes americanus. Fish Bull 73:431-438

Tamaru CS, Lee CS, Kelley CD, Banno JE, Ha PY, Aida K, Hanyu L (1988) Characterizing the stage of maturity most receptive to an acute LHRH-analogue therapy for inducing milkfish (Chanos chanos) to spawn. Aquaculture 74:147-163

Wang Y, Hu M, Cheung SG, Shin PKS, Song L, Wang W (2010) Induced ovulation of yellow catfish (Pelteobagrus fulvidraco) using a combination of a gonadotrop-releasing hormone analogue and domperidone. Aquac Res 41:1243-1249

Young G, Crim LW, Kagawa H, Kambegawa A, Nagahama Y (1983) Plasma 17 $\alpha, 20 \beta$-dihydroxy-4-pregnen-3-one levels during sexual maturation of amago salmon (Oncorhynchus rhodurus): correlation with plasma gonadotropin and in vitro production by ovarian follicles. Gen Comp Endocrinol 51:96-105

Zohar Y, Mylonas C (2001) Endocrine manipulation of spawning in cultured fish: from hormones to genes. Aquaculture 197:99-136 